\title{
Prevalence and correlates of depression and anxiety among patients with HIV on- follow up at Alert Hospital, Addis Ababa, Ethiopia
}

Getachew Tesfaw ${ }^{1 *}$, Getinet Ayano², Tadesse Awoke³, Dawit Assefa², Zelalem Birhanu ${ }^{3}$, Getenet Miheretie ${ }^{4}$ and Genet Abebe

\begin{abstract}
Background: Depression and anxiety disorders are common among people living with Human Immunodeficiency Virus than the non-infected individuals. The co-existence of these disorders are associated with barriers to treatment and worsening medical outcomes, including treatment resistance, increased risk for suicide, greater chance for recurrence and utilization of medical resources and/or increase morbidity and mortality. Therefore, assessing depression and anxiety among HIV patients has a pivotal role for further interventions.

Methods: Institution based cross-sectional study was conducted at ALERT hospital May, 2015. Data were collected using a pretested, structured and standardized questionnaire. Systematic sampling technique was used to select the study participants. Binary logistic regression analysis was used to identify associated factors. Odds ratio with $95 \% \mathrm{Cl}$ was computed to assess the strength of associations.

Results: The prevalence of co-morbid depression and anxiety among HIV patients was $24.5 \%$ and prevalence of depression and anxiety among HIV patients was $41.2 \%$ (172) and $32.4 \%$ (135) respectively. Multivariate analysis showed that individual who had perceived HIV stigma (AOR $=3.60,95 \% \mathrm{Cl}(2.23,5.80)$, poor social support $(A O R=2.02,95 \% \mathrm{Cl}(1.25,3.27)$, HIV stage III $(A O R=2.80,95 \% \mathrm{Cl}(1.50,5.21)$ and poor medication adherence (AOR $=1.61$, $95 \% \mathrm{Cl}(1.02,2.55)$ were significantly associated with depression. Being female (AOR $=3.13,95 \% \mathrm{Cl}(1.80,5.44)$, being divorced ( $A O R=2.51,95 \% \mathrm{Cl}(1.26,5.00)$, having co morbid TB (AOR $=2.74,95 \% \mathrm{Cl}(1.37,5.47)$ and perceived HIV stigma ( $A O R=4.00,95 \% \mathrm{Cl}(2.40,6.69)$ were also significantly associated with anxiety.

Conclusion: Prevalence of depression and anxiety was high. Having perceived HIV stigma, HIV Stage III, poor social support and poor medication adherence were associated with depression. Whereas being female, being divorced and having co morbid TB and perceived HIV stigma were associated with anxiety. Ministry of health should give training on how to screen anxiety and depression among HIV patients and should develop guidelines to screen and treat depression and anxiety among HIV patients.
\end{abstract}

Keywords: Depression, Anxiety, HIV/AIDS

\footnotetext{
* Correspondence: getachewtesfaw@gmail.com

'Department of psychiatry, Felege Hiwot Referral hospital, Bahirdar

University, Bahirdar, Ethiopia

Full list of author information is available at the end of the article
}

(c) The Author(s). 2016 Open Access This article is distributed under the terms of the Creative Commons Attribution 4.0 International License (http://creativecommons.org/licenses/by/4.0/), which permits unrestricted use, distribution, and reproduction in any medium, provided you give appropriate credit to the original author(s) and the source, provide a link to the Creative Commons license, and indicate if changes were made. The Creative Commons Public Domain Dedication waiver (http://creativecommons.org/publicdomain/zero/1.0/) applies to the data made available in this article, unless otherwise stated. 


\section{Background}

Currently, global statistics shows that an estimated 35 million people were living with HIV/AIDS in 2013, of which 24.7 million are living in Sub-Saharan Africa and 1.6 million people died related to AIDS [1]. In 2012 estimation, 9.5 million people in developing countries were receiving HIV treatment [2]. National prevalence in Ethiopia was $1.3 \%$ and 137 people receive ART in all ages [1].

There is a significant psychological impact imposed among HIV/AIDS patients. People with HIV often suffer from depression and anxiety as they adjust to the impact of the diagnosis of being infected and face the difficulties like shortened life expectancy, complicated therapeutic regimens, stigmatization, and loss of social and family support. HIV infection can also be associated with high risk of suicide [3-5].

Depression is a common mental disorder that presents with depressed mood, loss of interest or pleasure, decreased energy, feelings of guilt or low self-worth, disturbed sleep or appetite, and poor concentration [6]. Approximately, 350 million people are currently living with depression [6]. It is the fourth leading cause of disability worldwide and it will become the second leading cause of disability by 2020 [7]. Its life time prevalence was estimated to be approximately 3 to $17 \%$ [8].

In Ethiopia the survey done in nine regions reported, the prevalence of depressive episode was $9.1 \%$, which was associated with age, divorced, widowed, and alcohol drinking status and women are two times affected as compared to men with depression $[9,10]$.

Anxiety is a vague, subjective, non-specific feeling of uneasiness, apprehension, tension, (excessive nervousness) fears, and a sense of impending doom, irrational avoidance of objects or situations and anxiety attack [6]. It was associated with gender, age, and chronic diseases [11]. Women were affected nearly two times as compared to men by anxiety [8].

Depression and anxiety disorders are common in HIV infected individuals than general population [5]. Depression always coming with the symptom of anxiety and they have cause and effect relationship with chronic diseases [6, 12]. Depressive disorder was three times more common among HIV infected individuals and its lifetime prevalence estimate was 22-45 \% [12, 13]. Depression among HIV patients leads to low adherence to medical treatment, an increase health cost disability and mortality [14]. HIV/AIDS infected individuals are more prone for depression and anxiety disorders which, in turn, increase stigmatization, decrease quality of life, increase mortality, reduce adherence and impair their immune function [15].

Risk factors associated with depression and anxiety among HIV infected patients were low income, unemployment, alcohol use, poor medication adherence, HIV/AIDS stage, perceived stigma and social support [16-18]. Even though the co-morbidity of depression and anxiety among HIV/AIDS patients is a major cause of morbidity and mortality in developing countries like Ethiopia, little attention is given for their diagnosis. Therefore, the finding of this study will link the gap in making necessary solution by assessing the prevalence and factors associated with depression and anxiety among people living with HIV/AIDS patients in the study area.

\section{Methods \\ Study setting and design}

Institution based cross-sectional study was conducted at ALERT hospital May, 2015,Addis Ababa, Ethiopia.

\section{Study population}

The study population consisted of all adult HIV patients who were on follow up at ALERT hospital who were included in the sample. Those HIV patients who were critically ill were excluded from the study.

\section{Sampling procedures}

Sample size was determined based on single population proportion formula using Epi-info version 7 with a $95 \% \mathrm{CI}$, $5 \%$ margin of error and taking prevalence of depression and anxiety $43.9 \%$ [19] and $22.2 \%$ [20] respectively. Assuming a $10 \%$ non-response rate a total sample size of 417 HIV cases was required. Systematic sampling technique was used to select the study participants. Sampling interval was determined by dividing the total study population who had follow-up during four weeks data collection period by total sample size then the starting point was randomly selected.

\section{Data collection}

Data were collected using pretested interviewer administered questionnaire, which contains socio-demographic characteristics (age, education, occupation, marital status and others), Perceived HIV stigma (patients who scored greater than or equal to mean $(\geq 18.66$ or $\geq 5.54)$ on 11 item perceived HIV stigma scale), Social support (individuals who were scored greater than or equal to 9 (moderate and strong) on Oslo 3- item social support scale), Depression (depression was measured by using seven items of (depression sub scale) of Hospital Anxiety and Depression Scale (HADS)with cut-off points of greater than or equal to 8 scores) and Anxiety (anxiety was measured by using seven items of (anxiety sub scale) HADS with cut-off points of greater than or equal to 8 scores).

\section{Data processing and analyses}

Data were analyzed using SPSS version 20. Description of means, frequencies, proportions and rates of the given 
data for each variable was calculated. Bivariate analysis was done to see the association of each independent variable with the outcome variable. Those variables having $p$-value less than 0.2 were entered into the multivariate logistic regression model to identify the effect of each independent variable with the outcome variables. A $p$-value of less than 0.05 was considered statistically significant, and adjusted odds ratio with $95 \%$ CI was calculated to determine association.

\section{Ethical consideration}

Ethical clearance was obtained from the Institutional Review Board of the University of Gondar and Amanuel Mental Specialized. A formal letter of permission was obtained from Amanuel mental specialized hospital and University of Gondar was submitted to AHRI/ALERT ethical review committee for getting ethical clearance to do on the site. Supportive letter was obtained from AHRI/ALERT. Written informed consent was obtained from each study participant after they were introduced to the purpose of the study and informed about their rights to interrupt the interview at any time. Participants were informed that the information collected for this research project were kept confidential and information about collected by this study will be stored in a file, without their name, but code number assigned to it. It will not be revealed to anyone except the principal investigator and during final dissemination of aggregate results on workshops, publications and the like. Any individual level clinical data will not be disseminated for any one and it will be kept locked with key. HIV/AIDS patients who were found to have depression and anxiety were referred for further investigations.

\section{Results}

\section{Socio-economic and demographic characteristics}

A total of 417 participants were included in the study which makes the response rate $100 \%$. Themean age of the respondents was 37.44 $( \pm$ standard deviation $=10.07)$ years.

Among total participants, 251 (60.2 \%) were female, 149 (35.7\%) were married,157 (37.7 \%) were between the ages of 30-39 years. One third of the participants $33.8 \%$ attended primary education, Orthodox Christianity accounts for $302(76.7 \%)$ and around half of the participants $48.4 \%$ were Amhara by ethnicity. The median monthly income of the participants were 1000 birr and ranges from 100 to 9100 Ethiopian birr (Table 1).

Clinical and psychosocial characteristics of the respondents Regarding clinical characteristics of study participants, 390 (93.5 \%) had known their HIV sero positive status greater than for 12 months before the time of data collection. Around three fourth $(72.4 \%)$ of respondents were with CD4 count less than or equal to 500 cells $/ \mu \mathrm{L}$.
Table 1 Distribution of HIV/AIDS patients by socio-demographic factors at ALERT hospital ART clinic in, $2015(n=417)$

\begin{tabular}{|c|c|c|c|}
\hline Variables & Categories & Frequency & Percent (\%) \\
\hline \multirow[t]{2}{*}{ Sex } & Male & 166 & 39.8 \\
\hline & Female & 251 & 60.2 \\
\hline \multirow[t]{4}{*}{ Age } & $18-29$ & 85 & 20.4 \\
\hline & $30-39$ & 157 & 37.7 \\
\hline & $40-49$ & 116 & 27.8 \\
\hline & $\geq 50$ & 59 & 14.1 \\
\hline \multirow[t]{4}{*}{ Marital status } & Single & 130 & 31.2 \\
\hline & Divorced & 69 & 16.5 \\
\hline & Widowed & 69 & 16.5 \\
\hline & Married & 149 & 35.7 \\
\hline \multirow[t]{4}{*}{ Education } & Unable to read and write & 93 & 22.3 \\
\hline & Primary & 141 & 33.8 \\
\hline & Secondary & 137 & 32.9 \\
\hline & Above secondary & 46 & 11 \\
\hline \multirow[t]{4}{*}{ Religion } & Orthodox & 302 & 76.7 \\
\hline & Muslim & 59 & 14.2 \\
\hline & Protestant & 32 & 7.7 \\
\hline & Catholic & 6 & 1.4 \\
\hline \multirow[t]{4}{*}{ Ethnicity } & Amhara & 202 & 48.4 \\
\hline & Oromo & 98 & 23.5 \\
\hline & Gurage & 78 & 18.7 \\
\hline & Tigre & 39 & 9.4 \\
\hline \multirow[t]{6}{*}{ Occupation } & governmental employee & 73 & 17.5 \\
\hline & Private employee & 112 & 26.9 \\
\hline & House wife & 56 & 13.5 \\
\hline & Merchant & 46 & 11 \\
\hline & Daily labor & 46 & 11 \\
\hline & Student & 84 & 20.1 \\
\hline \multirow[t]{2}{*}{ Income } & $<1260$ & 244 & 58.5 \\
\hline & $\geq 1260$ & 173 & 41.5 \\
\hline
\end{tabular}

Half of study participants $48.2 \%$ had WHO clinical stage I. From all study participants, 256 (61.4\%) had poor social support, 254 (58 \%) had perceived HIV stigma and half of the respondents $50.1 \%$ had poor medication adherence. From all study participants 50 (12\%) had co-morbid TB and100 (24\%) were currently substance (khat, cigarette and alcohol) users (Table 2).

\section{Prevalence of depression and anxiety among HIV/AIDS patients}

The prevalence of co-morbid depression and anxiety among HIV patients in this study was $24.5 \%$. The prevalence of depression and anxiety among HIV patients in this study was $41.2 \%$ (172) and $32.4 \%$ (135) respectively. 
Table 2 Distribution of clinical, psychosocial, medication adherence and substance use factors among patients with PLWHA at ALERT hospital ART clinic in, $2015(n=417)$

\begin{tabular}{llll}
\hline Variables & Categories & Frequency & Percent (\%) \\
\hline Duration to know HIV status & $\leq 12$ months & 27 & 6.5 \\
& $>12$ months & 390 & 93.5 \\
CD4 count & $\leq 500$ & 302 & 72.4 \\
& $>500$ & 115 & 27.6 \\
Stage of HIV/AIDS & I & 201 & 48.2 \\
& II & 121 & 29 \\
Comorbid disease & III & 77 & 18.5 \\
& IV & 18 & 4.3 \\
TB & 50 & 12 \\
Good social support & Others & 45 & 10.8 \\
Perceived HIV stigma & No & 322 & 77.2 \\
& Good & 161 & 38.6 \\
Medication adherence & Poor & 256 & 61.4 \\
Yes & 242 & 58 \\
Substance ever use & No & 175 & 42 \\
& Good & 204 & 49.9 \\
& Poor & 213 & 50.1 \\
& No & 142 & 34 \\
& Yes & 275 & 66 \\
& No & 317 & 76 \\
& Yes & 100 & 24 \\
\hline
\end{tabular}

Factors associated with depression \& anxiety among patients with HIV/AIDS

Multivariate logistic regression analysis revealed that having HIV perceived stigma, poor medication adherence, HIV stage III and poor social support were significantly associated with depression. Being female, being divorced and having HIV perceived stigma and co morbid TB illness were significantly associated with anxiety.

By using multivariate logistic regression individuals having poor social support $(\mathrm{AOR}=2.02$, $95 \% \mathrm{CI}(1.25$, 3.27)) were associated with depression, those who had poor social support 2times more likely to develop depression than those who had good social support. Having HIV stage III (AOR $=2.80,95 \%$ CI $(1.50,5.21)$ were associated with depression. being on HIV stage III was2.8times more likely to exposed depressions compared to that of HIV stage I.

Similarly, having HIV perceived stigma had 3.6 times more likely to have depression as compared to patients who did not report perceived stigma $(\mathrm{AOR}=3.60,95 \% \mathrm{CI}$ $(2.23,5.80))$. Patients who had poor medication adherence $(\mathrm{AOR}=1.61,95 \% \mathrm{CI}(1.02,2.55)$ were associated with depression. Those with poor medication adherence were 1.6times more likely to develop depression as compared to that of good medication adherence (Table 3).

During multivariate logistic regression being female were 3 times $(\mathrm{AOR}=3.13$, $95 \% \mathrm{CI}(1.80,5.44))$ more likely to develop anxiety compared to male and being divorced were 2.5times $(\mathrm{AOR}=2.51,95 \% \mathrm{CI}$ (1.26, 5.00)) more likely to develop anxiety compared with married. Among clinical factors co morbid TB illness had 2.7times $(\mathrm{AOR}=2.74,95 \% \mathrm{CI}(1.37,5.47))$ more likely to develop anxiety as compared to that of no co morbid illness. Additionally, being stigmatized (AOR = 4.00, 95 \% CI $(2.40,6.69))$ were associated with anxiety.

Table 3 Factors associated with depression among HIV patients at ALERT hospital ART clinic in, $2015(n=417)$

\begin{tabular}{|c|c|c|c|c|}
\hline \multirow[t]{2}{*}{ Explanatory variables } & \multicolumn{2}{|c|}{ Depression } & \multirow[t]{2}{*}{ COR, 95 \% (Cl) } & \multirow[t]{2}{*}{ AOR, 95 \% (Cl) } \\
\hline & Yes & No & & \\
\hline \multicolumn{5}{|l|}{$\overline{\text { Age }}$} \\
\hline $18-29$ & 48 & 37 & $2.03(1.03,3.99)$ & $1.91(.87,4.18)$ \\
\hline $30-39$ & 58 & 99 & $0.92(0.49,1.69)$ & $1.02(0.50,2.08)$ \\
\hline $40-49$ & 43 & 73 & $0.92(0.48,1.76)$ & $1.20(0.58,2.52)$ \\
\hline$\geq 50$ & 23 & 36 & 1 & 1 \\
\hline \multicolumn{5}{|l|}{ Educational status } \\
\hline $\begin{array}{l}\text { Unable to read and } \\
\text { write }\end{array}$ & 50 & 37 & $2.33(1.33,4.78)$ & $2.05(0.83,5.09)$ \\
\hline Primary education & 57 & 85 & $1.15(0.59,2.26)$ & $1.00(0.44,2.23)$ \\
\hline Secondary education & 47 & 92 & $0.88(0.45,1.73)$ & $0.94(0.43,2.06)$ \\
\hline Diploma and above & 18 & 31 & 1 & 1 \\
\hline \multicolumn{5}{|l|}{ Stage of HIV } \\
\hline Stage one & 64 & 137 & 1 & 1 \\
\hline Stage two & 47 & 74 & $1.36(0.85,2.18)$ & $1.66(0.98,2.83)$ \\
\hline Stage three & 49 & 28 & $3.75(2.16,6.50)$ & $2.80(1.50,5.21)^{*}$ \\
\hline Stage four & 12 & 6 & $4.28(1.54,11.92)$ & $3.03(0.92,9.98)$ \\
\hline \multicolumn{5}{|l|}{ CD4 cell count } \\
\hline$<=500 \mathrm{cell} / \mu \mathrm{L}$ & 137 & 165 & $1.90(1.20,3.00)$ & $1.39(0.82,2.37)$ \\
\hline$>500$ cell/ $/ \mu \mathrm{L}$ & 35 & 80 & 1 & 1 \\
\hline \multicolumn{5}{|l|}{ Perceived stigma } \\
\hline Yes & 130 & 112 & $3.68(2.39,5.65)$ & $3.60(2.23,5.80)^{* *}$ \\
\hline No & 42 & 133 & 1 & 1 \\
\hline \multicolumn{5}{|l|}{ Medication adherence } \\
\hline Poor & 106 & 107 & $2.07(1.39,3.08)$ & $1.61(1.02,2.55)^{*}$ \\
\hline Good & 66 & 138 & 1 & 1 \\
\hline \multicolumn{5}{|l|}{ Social support } \\
\hline Good & 44 & 117 & 1 & 1 \\
\hline Poor & 128 & 128 & $2.66(1.74,4.06)$ & $2.02(1.25,3.27)^{*}$ \\
\hline
\end{tabular}

$P$-value for hosmer and lemeshew test $=0.402$ depression Others comorbid illness = diabetes mellitus, hypothyroidism, epilepsy and hypertension

Significant association $\left({ }^{*}=p\right.$-value $<0.05$ and ${ }^{* *}=p$-value $\left.<0.01\right)$, $n=$ sample size 
Those with stigmatized had 4times more likely develop anxiety as compared with not stigmatized (Table 4).

\section{Discussion}

This study revealed that the prevalence of co-morbid depression and anxiety was $24.5 \%$. Specifically, $41.2 \%$ had depression and $32.4 \%$ had anxiety. Perceived HIV stigma, poor social support, HIV stage III and poor medication adherence were significantly associated with depression. Being female, being divorced, having co morbid TB illness and perceived HIV stigma were also significantly associated with anxiety.

The prevalence of depression in the present study was $41.2 \%$. Regarding to prevalence, the current study result is line with other studies carried out in two areas of Ethiopia, USA and Denmark, in which the prevalence

Table 4 Factors associated with anxiety among HIV patients at ALERT hospital ART clinic, $2015(n=417)$

\begin{tabular}{|c|c|c|c|c|}
\hline \multirow[t]{2}{*}{ Explanatory variables } & \multicolumn{2}{|c|}{ Anxiety } & \multirow[t]{2}{*}{ COR, $95 \%(\mathrm{Cl})$} & \multirow[t]{2}{*}{ AOR, $95 \%(C l)$} \\
\hline & Yes & No & & \\
\hline \multicolumn{5}{|l|}{ Sex } \\
\hline Male & 30 & 136 & 1 & 1 \\
\hline Female & 105 & 146 & $3.26(2.04,5.21)$ & $3.13(1.80,5.44)^{* *}$ \\
\hline \multicolumn{5}{|l|}{ Marital status } \\
\hline Single & 39 & 91 & $1.25(0.74,2.12)$ & $1.14(0.62,2.10)$ \\
\hline Divorced & 32 & 37 & $2.53(1.39,4.60)$ & $2.51(1.26,5.00)^{*}$ \\
\hline Widowed & 26 & 43 & $1.77(0.96,3.25)$ & $1.31(0.65,2.61)$ \\
\hline Married & 38 & 111 & 1 & \\
\hline \multicolumn{5}{|l|}{ Occupational status } \\
\hline Student & 34 & 40 & $2.51(1.28,4.92)$ & $1.89(0.84,4.24)$ \\
\hline Daily labor & 17 & 29 & $1.73(0.80,(3.76)$ & $1.37(0.56,3.35)$ \\
\hline Merchant & 10 & 36 & $0.82(0.35,1.93)$ & $1.08(0.41,2.90)$ \\
\hline House wife & 18 & 38 & $1.40(0.66,2.95)$ & $0.78(0.32,1.89)$ \\
\hline Private employee & 35 & 77 & $1.34(0.71,2.53)$ & $1.26(0.60,2.62)$ \\
\hline Government employee & 21 & 62 & 1 & 1 \\
\hline \multicolumn{5}{|l|}{ Comorbid disease with HIV } \\
\hline TB & 24 & 26 & $2.21(1.21,4.01)$ & $2.74(1.37,5.47)^{*}$ \\
\hline Others & 16 & 29 & $1.32(0.68,2.54)$ & $1.38(0.66,2.88)$ \\
\hline No disease & 95 & 227 & 1 & \\
\hline \multicolumn{5}{|l|}{ Perceived stigma } \\
\hline Yes & 105 & 137 & $3.70(2.32,5.92)$ & $4.00(2.40,6.69)$ \\
\hline No & 30 & 145 & 1 & $* *$ \\
\hline \multicolumn{5}{|l|}{ Good social support } \\
\hline Yes & 48 & 134 & 1 & 1 \\
\hline No & 87 & 148 & $1.64(1.01,2.50)$ & $1.25(0.76,2.05)$ \\
\hline
\end{tabular}

$P$-value for hosmer and lemeshew test $=0.540$

Others co morbid illness = diabetes mellitus, hypothyroidism, epilepsy and hypertension

Significant association $\left(^{*}=p\right.$-value $<0.05$ and ${ }^{* *}=p$-value $\left.<0.01\right)$ estimates were reported to be $38.94,43.9,44,38 \%$ respectively [20-23].

On the other hand, the present study findings was lower than the studies done in Albanian, China, India and Cameron in which the prevalence's were reported to be $58.75,73.1,66.3$ and $63 \%$ respectively [18, 24-26]. The variation of the prevalence might be due to different sample size used and different instruments used to assess depression. Only 100 participants were included in Cameron and PHQ-9 with the cutoff point greater than or equal to 9 [26], 320 participants in china and using CES-D with the cutoff points greater than or equal to16 [18], in India 160participants and using CES-D [24] and about 79 participants in Albania [25].

The result of the study was higher than the studies conducted in south Africa, Ghana, Nigeria, USA, Brazil, India, in which the prevalence were reported to be $25.4,5.4,23.1,32,14.15$ and $35.5 \%$ respectively [16-22, 24, 26-42]. The use different measurement tools used to assess depression and sample size difference that were in Ghana using DASS greater than or equal to 10 and 107 participants [37], in Nigeria 130 participants and using clinical interview DSM-IV [19] and in India using BDI-II and 152 participants [27].

Regarding to associated factors, having HIV stage III was associated with depression, which was 2.8 times more likely to develop depression as compared to that of HIV stage one patients. This was supported with the study done at Debirebirhan hospital in Ethiopia [21].

Perceived HIV stigma was strongly associated with depression in this study, which was 3.6 times having depression as compared with non-stigmatized HIV patients, which was supported with the studies done in Ethiopia at Debirbirahan hospital and USA [21, 35]. Stigma increase levels of fatigue and decrease attention or felling of worthlessness [35].

Having poor social support was 2 times more likely to develop depression as compared with those who had good social support that was comparable with the studies done in Ghana, India and two areas in china [17, 18, 43, 19]. HIV/AIDS patients preferred to avoid seeking help from others and avoid opening up about their health due to social stigma towards themselves, which increases their isolation and loneness $[18,19]$.

Having poor medication adherence was 1.6 times more likely to develop depression compared with those who had good medication adherence. This was supported by the study done in USA that was perceived HIV stigma and depression were the two interconnected factors that were aggravated poor medication adherence [35].

The prevalence of anxiety in this study was $32.4 \%$, which was similar to the studies done in USA, South Africa, Canada and western Europe together, in which 
the prevalence were reported to be $33,30.6,33.4,33.3 \%$ respectively [16, 27, 37, 44].

On the other hand, the current study findings was lower than the studies done in Albanian and two areas of china, in which the prevalence were reported to be $82.3,45.6,49 \%$ respectively $[18,25,43]$. The possible reason might be the difference of tools used to assess anxiety and different sample size used. Which was 320 and 800 participants in two areas of China respectively and the same measurement tool used to assess anxiety, which was Zung self-rating anxiety scale with the cut of points greater than or equal to 50 and greater than or equal to 40 respectively.

Additionally, our findings was higher than the studies done in Ethiopia at Debrebirhan hospital, Ghana, Thailand, Brazil and Asia, in which the prevalence were reported to be $22.2,7.2,16.3,12.6,20.3 \%$ respectively [ $30,37,45,46$, 19]. The above prevalence variations might be due to the difference in sample size used and different measurement tools used to assess anxiety. In Ethiopia and Brazil studies done to assessed the prevalence of anxiety by using BAI greater than or equal to 22 and 436 and 346 of their study participants respectively. In Thailand to assessed anxiety symptoms by using HADS with the cut of points greater than or equal to 11 and 251 participants and in Ghana used to assess anxiety by using DASS with the cut of points greater than or equal to 8 and 107 participants.

Being female had 3 times to develop anxiety as compared to male that was similar to the studies done in Ethiopia and Ghana [30, 35]. Being female is the exposure of acute life experience, low social interaction and had less social support from friends and families might be increased risk of anxiety [30, 35].

The present study revealed that being divorced was significantly associated with anxiety. In this study, being divorce was 2.5 times risk of developing anxiety as compared to married. This study was supported study done at Debretabor hospital in Ethiopia that was one of the outcome of divorce was affects the whole family structure and which leads to low self-confidence and financial problem [30].

Having TB/HIV co-infection had 2.7 times risk of developing anxiety as compared with those who had no co morbid illness. The possible reason might be drug-drug interaction, increase adverse effects and co-infection leads to high level of stigma and discrimination by verbal, gossip and name calling may lead to high rate of anxiety.

HIV perceived stigma had 4 times risk of developing anxiety as compared with those who had non-stigmatized HIV patients. This outcome was consistent by the studies done in Ethiopia and South Africa that were stigma was associated with anxiety $[27,30]$.

\section{Conclusion}

The prevalence of co-morbid depression and anxiety $(24.6 \%)$, and prevalence of depression $(41.2 \%)$ and anxiety (32.4 \%) was high. Having perceived HIV stigma, HIV Stage III, poor social support and poor medication adherence were significantly associated with depression. Whereas being female, being divorced, having co morbid TB and perceived HIV stigma were associated with anxiety. Ministry of Health should develop guidelines to screen and treat depression and anxiety among TB patients. Further research on risk factors of depression and anxiety should be conducted to strengthen and broaden these findings.

\section{Acknowledgements \\ The authors acknowledge Amanuel Mental Specialized Hospital, Ethiopia for funding the study. The authors appreciate the respective study institutions and the study participants for their cooperation in providing the necessary information.}

\section{Funding}

This research work is funded by Amanuel Mental Specialized Hospital.

\section{Availability of data and materials}

The datasets during and/or analysed during the current study available from the corresponding author on reasonable request.

\section{Authors' contributions}

GT conceived the study and was involved in the study design, reviewed the article, analysis, report writing and drafted the manuscript GA, DA, ZB, GM, GA \& TA were involved in the study design, analysis and drafted the manuscript. All authors read and approved the final manuscript.

\section{Competing interests}

The authors declare that they have no competing interests.

\section{Consent for publication}

N/A.

\section{Ethics approval and consent to participate}

Ethical approval was obtained from the Institutional Review Board of the Alert hospital, University of Gondar and Amanuel Mental Specialized. Individuals who agreed to participate gave written consent. For those who were not literate, independent witnesses were invited to sign to indicate that the information had been read out correctly. Non-literate participants then gave a finger print to indicate consent. Confidentiality was maintained by omitting identifiers from the computer and privacy was ensured during interview. All participants were given an information sheet and were only included in the study after providing informed consent.

\section{Author details}

${ }^{1}$ Department of psychiatry, Felege Hiwot Referral hospital, Bahirdar University, Bahirdar, Ethiopia. ${ }^{2}$ Research and training department, Amanuel mental specialized hospital, Addis Ababa, Ethiopia. ${ }^{3}$ Institute of Public Health, College of Medicine and Health Sciences, University of Gondar, Gondar, Ethiopia. ${ }^{4}$ Department of psychiatry, College of Medicine and Health Sciences, University of Gondar, Gondar, Ethiopia. ${ }^{5}$ Department of non communicable diseases, Addis Ababa Health office, Addis Ababa, Ethiopia.

Received: 19 December 2015 Accepted: 9 September 2016 Published online: 02 November 2016

\footnotetext{
References

1. United Nation Aquired Immunodefeciency Syndrom (UNAIDS). The global AIDS epidemic. Geneva: UNAIDS; 2013.

2. United Nation. The millennium development goals report. New York: Nations EaSAotU; 2014.
} 
3. Sathia S. Trauma and mental health of HIV positive persons. Indian streams research Journal. 2013; 3(7).

4. Owe-Larsson B, Säll L, Salamon E, Allgulander C. HIV infection and psychiatric illness. Afr J Psychiatry. 2009;12:115-28.

5. World Health Organazation. HIV/AIDS and mental health report by the secretariat. Geneva: World Health Organazation; 2008. EB124/6.

6. World Health Organization. World suicide prevention day: 2012.

7. Benjamin JS, V A. Kaplan \& Sadock's Synopsis of Psychiatry: Behavioral Sciences/Clinical Psychiatry. Lippincott Williams \& Wilkins. 2007; 10th Edition: p.529.

8. Benjamin JS, Virgina AS. Synopsis of psychiatry text book. In: Rihmer Z, Angst A, editors. Comprehensive textbook of psychiatry 8th. 10th ed. Baltimore: Lippincott Willian and Wilikin; 2004. p. 529.

9. Kebede D, Alem A. Major mental disorders in Addis Ababa,Ethiopia : Affective disorders. Acta Psychiatr Scand. 1999:100:18-99.

10. Hailemariam S, Tessema F, Asefa M, Tadesse H, Tenkolu G. The prevalence of depression and associated factors in Ethiopia: findings from the National Health Survey. Int J Ment Health. 2012;6:23. doi:10.1186/1752-4458-6-23.

11. Gullichl I, Ramosl AB, Zanl TRA, Schererl C, Mendoza-Sassil RA. Prevalence of anxiety in patients admitted to a university hospital in southern Brazil and associated factors. Rev Bras Epidemiol. 2013;16(3):644-57.

12. DeJean D, Giacomini M, Vanstone M, Brundisini F. Patient experiences of depression and anxiety with chronic disease: A systematic review and qualitative meta-synthesis. Ont Health Technol Assess Ser. 2013;13(16):1-33.

13. Weissman MM, Bland RC, Canino GJ, Faravelli C, Greenwald S, Hwu HG, et al. Cross national epidemiology of major depression and bipolar disorder. JAMA. 1996;276:293-9.

14. World Health Organazation. Mental health and substance dependence, noncommunicable diseases and mental health. Geneva: World Health Organazation; 2003.

15. National Mental Health Strategy and Federal Ministry of Health. There is no health without mental health. Ethiopia: National Mental Health Strategy and Federal Ministry of Health; 2015.

16. Eshetu DA, Woldeyohannes SM, Alemayehu M, Techane GN, Tegegne MT, Dagne K. Prevalence of depression and associated factors among HIV/AIDS Patients attending ART Clinic at Debrebirhan referral hospital, North Showa, Amhara Region, Ethiopia. Am J Community Psychol. 2014;2(6):101-8.

17. Campos LN, Guimarães MDC, Remien RH. Anxiety and depression symptoms as risk factors for nonadherence to antiretroviral therapy in Brazil. AIDS Behav. 2011;14(2):289-99.

18. Bhate MS, Munjal S. Prevalence of depression in people living with HIV/AIDS undergoing ART and factors associated with it. J Clin Diagn Res. 2014;8(10): WC01-4.

19. Berhe H, Bayray A. Prevalence of depression and associated factors among people livingwith HIV/AIDSI in Tigray, Ethiopia. North Ethiopia: A crosssectional rosssectional hospital based study. IJPSR. 2013;4(2):765-75.

20. Belete A, Andaregie G, Tareke M, Birhan T, Azale T. Prevalence of anxiety and associated factors among people living with HIV/AIDS at Debretabor general hospital Anti Retro Viral clinic Debretabor, Amhara, Ethiopia. Am J Psychiatry Neurosci. 2014;2(6):109-14.

21. Rao D, Feldman BJ, Fredericksen RJ, Crane PK, Simoni JM, Kitahata MM, et al. A structural equation model of HIV-related stigma, depressive symptoms, and medication adherence. AIDS Behav. 2012;6(3):711-6.

22. Nüesch R, Gayet-Ageron A, Chetchotisakd P, Prasithsirikul W, Kiertiburanakul S, Munsakul W, et al. The impact of combination Antiretroviral Therapy and its interruption on anxiety, stress, depression and quality of life in Thai patients. Open AIDS J. 2009;3:35-45.

23. Pappin M, Wouters E, Booysen FL. Anxiety and depression amongst patients enrolled in a public sector antiretroviral treatment programme in South Africa: a crosssectional study. BMC Public Health. 2012;12:244.

24. Amiya RM, Poudel KC, Poudel-Tandukar K, Pandey BD, Jimba M. Perceived family support, depression, and suicidal ideation among people living with HIV/AIDS: A cross- sectional study in the Kathmandu Valley, Nepal. PLoS One. 2014;9(3), e90959. doi:10.1371/journal.pone.0090959.

25. Asante KO. Social support and the psychological wellbeing of people living with HIV/AIDS in Ghana. Afr J Psychiatry. 2012;15:340-5.

26. Martatino IY, Habibie R, Sahrah A, Wardhana AA. The innovative of aniety disorder healing:Nutri Moringa pudding for pudding for HIV/AIDS infected patients. Int J Asian Soc Sci. 2014;4(11):1100-9.

27. Aina Y, Susman JL. Understanding comorbidity with depression and anxiety disorders. J Am Osteopath Assoc. 2006;106(5 Suppl 2):S9-S14.
28. Pence BW, Gaynes BN, Williams Q, Riddhi Modi M, Adams J, Quinlivan EB, et al. The effect of measurement-based care depression treatment on HIV medication adherence and health outcomes. PMC. 2013;33(4):828-38.

29. Brandt R. The mental health of people living with HIV/AIDS in Africa: A systematic review. 2008. p. 231.

30. Reif S, Proeschold-Bell RJ, Yao J, Legrand S, Uehara A, Asiimwe E, Quinlivan EB. Three types of self-efficacy associated with medication adherence in patients with co-occurring HIV and substance use disorders, but only when mood disorders are present. J Multidiscip Healthc. 2013;6:229-37.

31. Gaynes BN, Pence BW, Jr JJE, Miller WC. Prevalence and comorbidity of psychiatric diagnoses based on reference standard in an HIV+ patient population. PMC. 2010;70(4):505-11.

32. Elbirt D, Bayon C, Robertson K, McNamara P, Kulasegaram R. Neurocognitive impairment, depression, and anxiety in HIV-1-infected patients across western Europe and Canada:the CRANlum study ethnicity analysis. J Int AIDS Soc. 2012;15(4):18276.

33. Robertsona K, Bayonb C, Molinac JM, McNamarae P, Reschf C, MuñozMorenog JA, et al. screening for neurocognitive impairment, depression, and anxiety in HIV infected patients in Western Europe and Canada. AIDS Care. 2014;26(12):1555-61.

34. Calvetti PÜ, Giovelli GRM, Gauer GJC, Moraes JFD. Psychosocial factors associated with adherence to treatment and quality of life in people living with HIV/AIDS in Brazil. J Braz Psychiat. 2014;63(1):8-15.

35. Rodkjaer L, Laursen T, Balle N, Sodeman M. Depression in patients with HIV is under-diagnosed:a cross-sectional study in Denmark. British HIV Assoc HIV Med. 2010;11:46-53.

36. Morrison SD, Banushi VH, Sarnquist C, Gashi HV, Osterberg L, Maldonado Y, et al. Levels of self-reported depression and anxiety among HIV-positive patients in Albania: a cross-sectional study. Croat Med J. 2011;52:622-8.

37. Liu L, Pang R, Sun W, Wu M, Qu P, Lu C, et al. Functional social support, psychological capital,and depressive and anxiety symptoms among people living with HIV/AIDS employed full-time. BMC Psychiatry. 2013;13:324. doi:10 1186/1471-244X-13-324.

38. Calvetti PÜ, Giovelli GRM, Gauer GJC, Moraes JFD. Psychosocial factors associated with adherence to treatment and quality of life in people living with HIV/Aids in Brazil. J Braz Psychiatry. 2014;63(1):8-15.

39. Reda AA. Reliability and Validity of the Ethiopian Version of the Hospital Anxiety and Depression Scale (HADS) in HIV Infected Patients. PLoS One. 2011;6(1), e16049. doi:10.1371/journal.pone.0016049.

40. Høgskole D, Postboks VO. Characteristics of senior centre users - and the impact of a group programme on social support and late-life depression. Norsk Epidemiologi. 2012;22(2):261-9.

41. Morisky DE, Green LW, Levine DM. Concurrent and predictive validity of a selfreporting measure of medication adherence. Med Care. 1986;24(1):67-74.

42. Rie AV, Sengupta S, Pungrassami P, Balthip Q, Choonuan S, Kasetjaroen Y, et al. Measuring stigma associated with tuberculosis and HIV/AIDS in southern Thailand: exploratory and confirmatory factor analyses of two new scales. Trop Med Int Health. 2008;13(1):21-30.

43. L'akoa RM, Noubiap JJ, Fang Y, Ntone FE, Kuaban C. Prevalence and correlates of depressive symptoms in HIV-positive patients: a cross-sectional study among newly diagnosed patients in Yaoundé, Cameroon. BMC Psychiatry. 2013;13:228. doi:10.1186/1471-244X-13-228.

44. Obadeji A, Ogunlesi AO, Adebowale TO. Prevalence and predictors of depression in people living with HIV/AIDS attending an outpatient clinic in Nigeria. Iran Psychiatry Behave Sci. 2014;8(1):26-31.

45. Sun W, Wu M, Qu P, Lu C, Wang L. Psychological well-being of people living with HIV/AIDS under the new epidemic characteristics in China and the risk factors:a population-based study. Int J Infect Dis. 2014;28:147-52.

46. Gohain Z, Halliday MAL. Internalized HIV-stigma, mental health, coping and perceived social support among people living with HIV/AIDS in Aizawl District-A pilot study. Psych. 2014;5:1794-812. 